\title{
Procedures in Practice
}

\section{EAR SYRINGING}

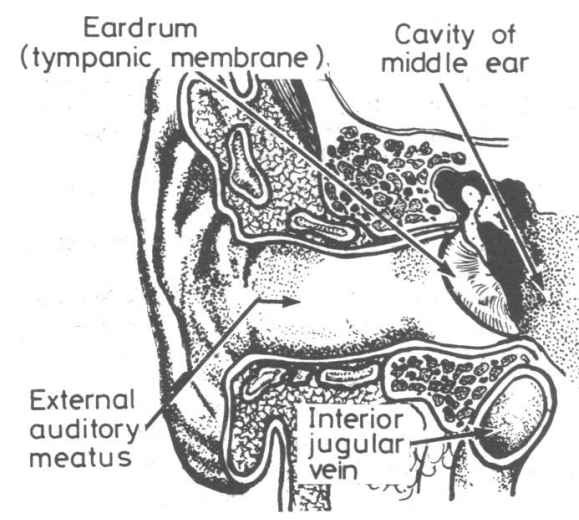

Indications

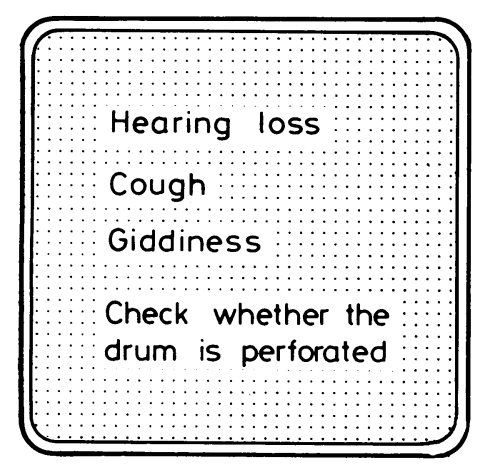

\section{Contraindications}

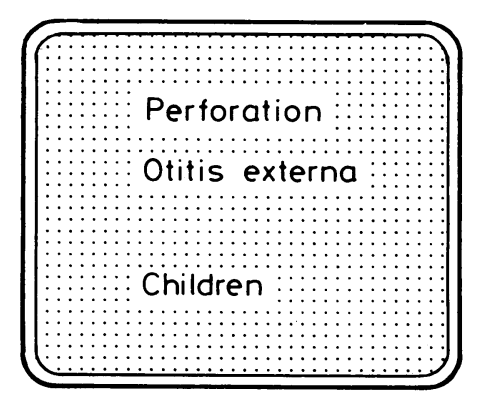

Wax (cerumen) is the secretion of the glands in the outer third of the external auditory meatus. Its consistency may be affected by atmospheric pollution. Normally it is expelled by ordinary chewing movements, but in some patients this does not happen. The wax then accumulates and may eventually block the external auditory meatus.

Symptomatic-(1) Hearing loss. (a) Acute onset: water in the ear may cause sudden swelling of the wax (for example, when swimming under water), which brings the patient rapidly to the doctor. (b) Gradual onset: the hearing loss may go unnoticed by the patient for a long time.

(2) Earache: when the wax is pressing on the drum. (3) Cough: when the wax is pressing on the auricular branch of the vagus nerve. (4) Giddiness: sometimes present when there is an obstruction by wax in one meatus only.

Asymptomatic-Wax is frequently seen on routine examination. If the examination is for an insurance or pre-employment medical it may be necessary to remove the wax to ascertain whether $(a)$ the hearing is normal and $(b)$ the drum is perforated. Plugs of wax that do not block the meatus (and hence cannot affect the hearing) and still enable the drum to be seen may safely be left. Sometimes a thin film of wax on the drum (not painful) may give the impression that there is a perforation.

Note-The ordinary process of syringing when the middle ear is not inflamed often causes a temporary redness of the drum, which may confuse the diagnosis.

The presence of a perforation is a contraindication. Unfortunately, many patients are unaware of the perforation and it may not be identified until after the ear has been syringed. If necessary a prophylactic antibiotic should be administered systemically. Otitis externa is usually regarded as a contraindication because water can aggravate it. Nevertheless, many experienced doctors still syringe the ears when this condition is present but would always be careful gently to mop the meatus dry and might also instil some steroid drops (for example, betamethasone valerate lotion) twice daily for three or four days after syringing.

Wax in the ears of children poses special problems. Syringing the ears in a child is never easy and is particularly difficult when the child is ill. Nor is the procedure free from risk of trauma, especially if the child is fractious. Many experienced practitioners prefer to treat the suspected diagnosis rather than risk physical and emotional trauma. 


\section{Equipment}
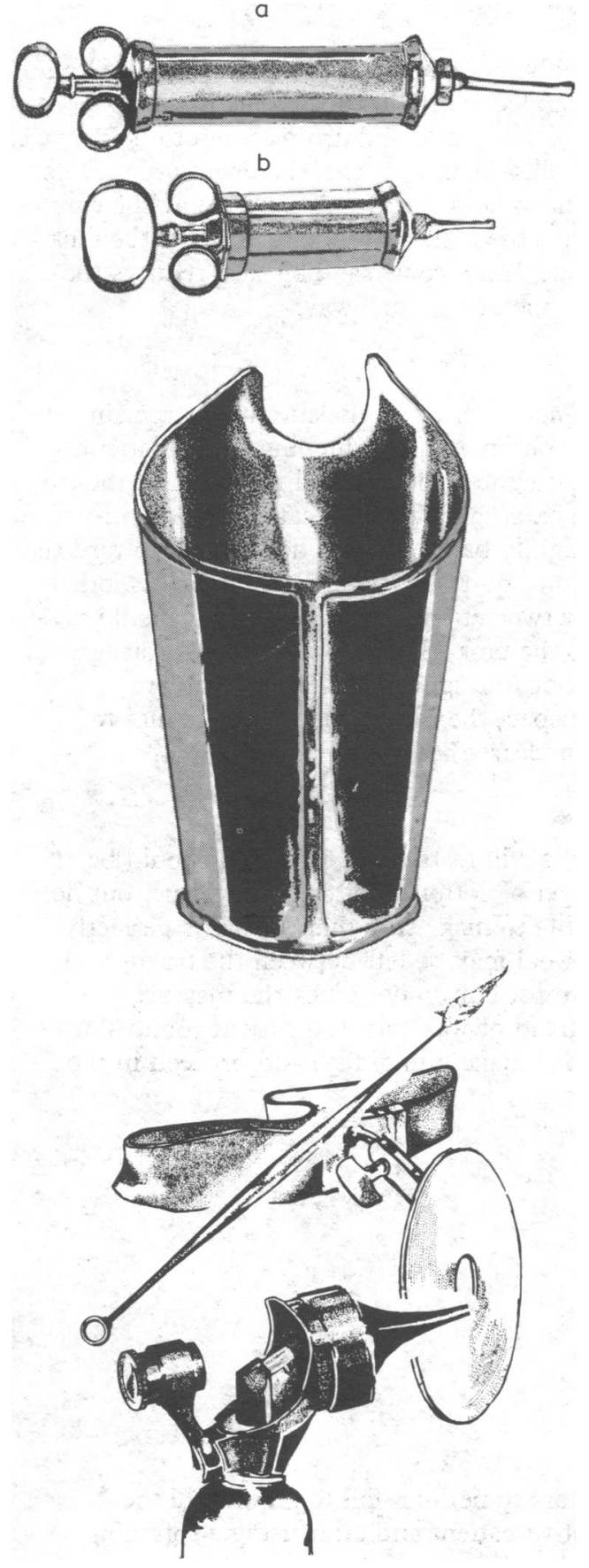

\section{Procedure}

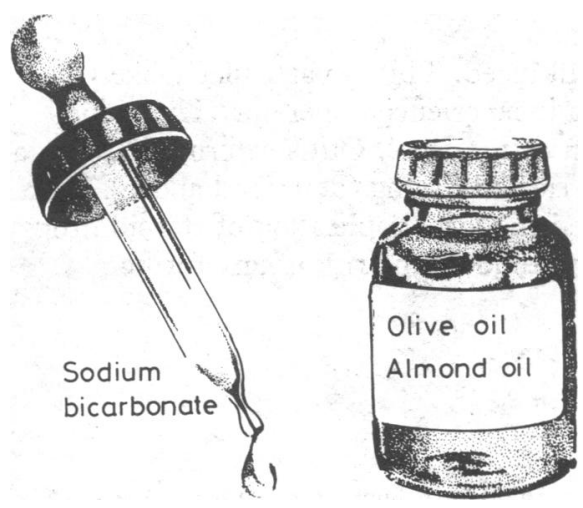

Syringe-Most ear syringes are about $18 \mathrm{~cm}$ long excluding the nozzle and hold about $120 \mathrm{ml}$ of water (a). Shorter syringes are available (b): though they hold less water they are easier to balance. Alternatively, a Higginson's syringe may be used. Sterility is not necessary.

Water-Plain tap water may be used and should be at or slightly above body temperature. The use of sodium bicarbonate in the water is not essential. Water that is too hot or too cold will stimulate the semicircular canals and may cause vertigo, nausea, and vomiting.

Towels-Traditionally a rubber or plastic apron is wrapped round the patient's neck to protect his clothes. The cost of laundering cloth towels normally prohibits their use, but paper towels are a satisfactory substitute. They may be tucked inside the collar and will soak up most, if not all, of any water that spills.

Collecting bucket-A Noot's tank is the most convenient, but if one is not available a kidney dish will do. The main disadvantage of the kidney dish is its habit of tipping over when partly full.

Wax hook-A wax hook (Jobson-Horne) is useful to lift out a plug of wax that remains obstinately in sight but keeps falling back or one that is stuck to the side wall of the meatus. In most patients experienced operators can remove all the ear wax with a hook without recoursing to syringing.

Lighting - A source of light, either a battery auriscope or a lamp, speculum, and head mirror, is essential for examining the ear before, during, and after the procedure. If a wax hook is to be used in the depths of the external auditory meatus a head mirror and speculum have an advantage over an electric auriscope in leaving one hand completely free to manipulate the hook.

Wax-softening agents-It is usually possible to syringe wax from an ear without any preparation, but first softening the wax eases the process. Sodium bicarbonate eardrops are effective. Alternatively, olive or almond oil or one of the proprietary preparations may be used. After any of these have been used for two to five days syringing may sometimes not be necessary. Some of the proprietary preparations, however, may cause otitis externa.
If the indications for removing wax are not urgent, prescribe a suitable solvent to be used in the affected ear(s) night and morning for two to five days and ask the patient to return at the end of that time. Alternatively, an immediate attempt to remove the wax may be made with a hook or by syringing the ear without preparation. There is some evidence that using a solvent solution for even half an hour before syringing may offer some benefit. 

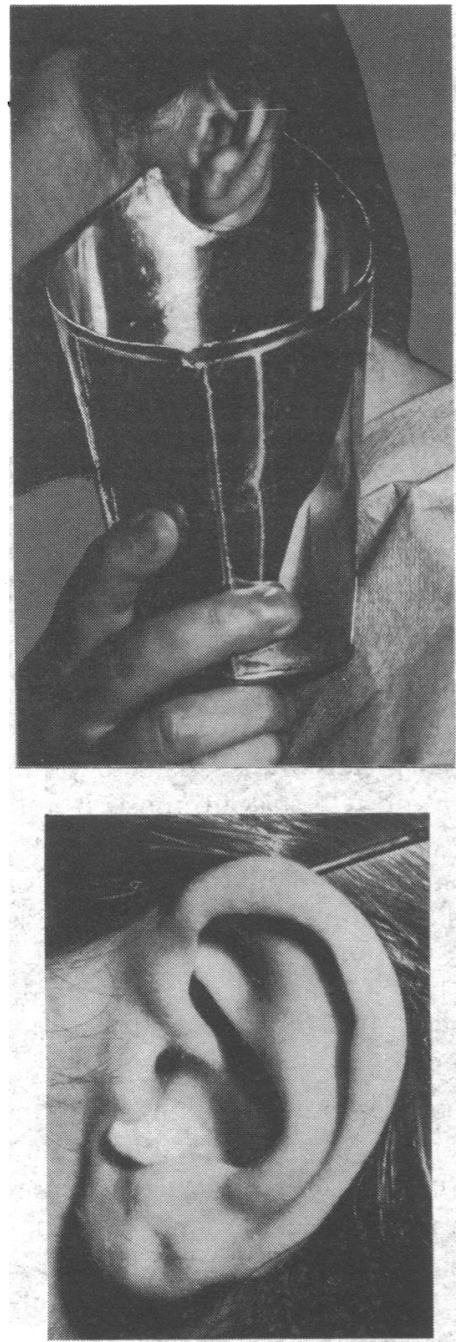

\section{Complications}

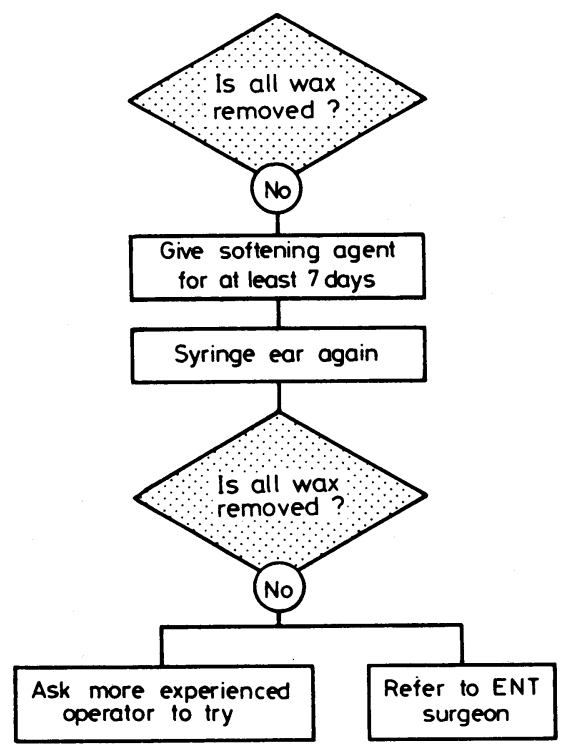

Have the patient sit comfortably in a chair, with his coat removed and a paper towel or plastic apron wrapped round his neck. The patient's co-operation is highly desirable if the meatus and drum are not to be damaged and water is not to be squirted all over the patient, the operator, and the rest of the room. Ask the patient to hold the Noot's tank below the ear, slotting the lobe into the groove. It is easier if the patient holds the tank to the right ear with the left hand and vice versa. This also reduces the risk of the patient knocking the operator's arm away.

When all is ready fill the syringe with water. Be sure no air remains in the syringe, as the sound of bubbles may be frightening to the patient. Pull the pinna up and back to straighten the external meatus. Put the tip of the nozzle at the edge of the external auditory meatus, pointed in the direction of the eardrum but slightly backward and downward (toward the patient's occiput). Some operators squirt the water in short bursts, others empty each syringeful in one or two actions. The jet of water should pass behind the wax and return into the tank. Sooner or later it will bring with it the lump of wax either intact or in fragments (often several large fragments: hence the need to inspect the ear during the procedure to ensure that all the wax has been cleared).

Water remaining in the meatus will restrict the view and should be gently mopped out with a pledget of cotton wool or paper tissue, but do not damage the eardrum in trying to make sure that the ear is perfectly dry. A small pledget of cotton wool may be left between the tragus and antitragus to mop up the last drops, but do not block the meatus.

When the first ear has been freed of wax turn the patient round slowly in his chair (rapid movement may make him giddy) and proceed in the same way with the other ear.
The most experienced operators sometimes fail to remove all the wax, even in the most co-operative patient and after using a softening agent. If the wax cannot be removed first time have the patient continue to use the softening agent for at least another seven days before repeating the procedure. If it again fails, ask a more experienced operator to try; alternatively, refer the patient to an ENT surgeon. Rarely, a general anaesthetic may be necessary.

If the meatus is scratched it will bleed. This is particularly likely to occur if a wax hook is used by an inexperienced operator. The blood should be gently mopped up with cotton wool. Otitis externa is always a risk, but this may be reduced by careful drying (described above). If an already affected meatus is syringed the local application of steroid drops for one or two days after syringing reduces the risk of any further exacerbation. 